www.jmscr.igmpublication.org

Impact Factor 5.244

Index Copernicus Value: 5.88

ISSN (e)-2347-176x ISSN (p) 2455-0450

crossref DOI:_http://dx.doi.org/10.18535/jmscr/v4i3.33

Journal Of Medical Science And Clinical Research

IGM Publication

An Official Publication of IGM Publication

\title{
Liver enzymes Alterations after Laparoscopic Cholecystectomy: A Prospective Study
}

\author{
Author \\ Bhavinder Arora \\ MS FIAMS FAIS, Associate Professor, PT BD Sharma PGIMS, Rohtak-124001 \\ Corresponding Author \\ Bhavinder Arora \\ 2156/5, Mal Godam Road, Rohtak - 124001 \\ Email: drbhavinderarora@gmail.com, Mobile: 9466290707
}

\begin{abstract}
Background: In laparoscopic cholecystectomy, carbon dioxide gas is used for insufflation into peritoneum. The carboxy peritoneum which is used to create space in laparoscopic cholecystectomy is kept at pressure of 10-15mm of $\mathrm{Hg}$. This high carboxy peritoneum pressure is likely to cause impedance in splanchnic perfusion and decrease the hepatic perfusion. This can lead to disturbances in liver functions.

Material and Methods: This study was done on a total of fifty patients presenting with symptomatic gall stone disease. Liver function tests were done in all the patients in pre operative and post operative period after laparoscopic cholecystectomy.

Results: Total serum bilirubin measured pre operative and post operative were compared, there was no significant change in the serum bilirubin levels. The serum AST levels were compared in preoperative and postoperative period and there was significant increase in level of serum AST. The serum ALT levels comparison between preoperative and postoperative values has shown significant change. The difference in serum alkaline phosphatase levels is also non significant.

Conclusion: This study concludes that transient elevation of liver enzymes does occur after laparoscopic cholecystectomy.

Keywords: Laparoscopic cholecystectomy, Hepatic enzymes, Carboxy peritoneum
\end{abstract}

\section{Introduction}

The open cholecystectomy has been replaced by laparoscopic cholecystectomy as a gold standard for treatment of gall stones. Laparoscopic cholecystectomy is considered to be a safe procedure as compared to open cholecystectomy in regards of metabolic, hormonal and immunological changes. In laparoscopic cholecystectomy, carbon dioxide gas is used for insufflation into peritoneum. The carboxy peritoneum which is used to create space in laparoscopic cholecystectomy is kept at pressure of $10-15 \mathrm{~mm}$ of $\mathrm{Hg}$. The normal portal pressure is $7-10 \mathrm{~mm}$ of $\mathrm{Hg}$. This high carboxy peritoneum pressure is likely to cause impedance in splanchnic perfusion and decrease the hepatic perfusion. This can lead to disturbances in liver functions. ${ }^{1}$ It appears that carboxy peritoneum 
pressure used is equal to normal portal vein pressure than these disturbances can be avoided. The liver function tests provide quantitative assessment of liver function but cannot differentiate between causes of liver diseases. However liver function tests are used to determine the presence of liver disease, diagnosis of liver diseases and monitoring of liver diseases. Several tests are used to detect the derangement of liver functions. The commonly used tests are Serum Bilirubin (S Bil), Alanine Aminotransferase (ALT), Aspartate Aminotransferase (AST), Alkaline Phosphatase (ALP). These enzymes normally concentrated in liver are also present in low concentration in plasma. The plasma concentration of these enzymes is determined by rate of release from liver cells and plasma clearance. High concentration of these enzymes in plasma is present when there is hepatocellular damage. The AST, ALT and AST: ALT ratio signifies hepatocellular damage, ALP signifies cholestasis and organic anion metabobolism. Pre operative and Post operative analysis of these tests can detect any alteration in liver functions following laparoscopic cholecystectomy. Several studies have shown alterations in liver function tests after laparoscopic cholecystectomy. These studies have attributed changes in liver function tests to hepatocellular damage due to carboxy peritoneum, liver manipulation, use of cautery, general anaesthesia and hepatic artery injury. ${ }^{2,3,4,5}$ This study was done to see the alteration in liver functions following laproscopic cholecystectomy.

\section{Material and Methods}

This study was done on a total of fifty patients presenting with symptomatic gall stone disease. The diagnosis of cholelithiasis was confirmed on ultrasonography. Patients with chronic liver diseases like cirrhosis were excluded from the study. Liver function tests were done in all the patients in pre operative and post operative period. The post operative liver function tests were done 24 hours after the surgery. The normal values of the liver function tests in our laboratory were used to compare the results of pre operative and post operative liver functions. Only patients with normal pre operative liver functions were included in this study. Standard four ports laparoscopic cholecystectomy was done in all the patients. The carbon dioxide gas was used to create pneumo peritoneum. The intraperitoneal pressure was kept around $12 \mathrm{~mm}$ of $\mathrm{Hg}$. The laparoscopic procedure which was converted to open was also excluded from the study. The study was planned in fifty patients undergoing laparoscopic cholecystectomy to see changes in liver function tests after surgery.

\section{Results}

In this study the patients were of the age group between 31 to 60 years. Most of the patients were females $80 \%$ while males were only $20 \%$. The average operating time was about one hour. The results of preoperative and postoperative values of serum bilirubin, AST, ALT and serum alkaline phosphatase are depicted in table 1.

\begin{tabular}{|l|l|l|l|}
\hline Liver Function Test & Preop Value + SD & Postop Value + SD & p Value-significance \\
\hline S Total Bilirubin & $0.78 \pm .213$ & $0.76 \pm .261$ & $.050-$ not significant \\
\hline AST & $28.2+6.4$ & $36.6 \pm 4.6$ & $.001-$ significant \\
\hline ALT & $29.1 \pm 8.6$ & $37.9 \pm 3.4$ & $.001-$ significant \\
\hline S Alk. Phosphatase & $86.7 \pm 1.2$ & $87.5 \pm 1.4$ & $.051-$ not significant \\
\hline
\end{tabular}

Total serum bilirubin measured pre operative and post operative were compared, there was no significant change in the serum bilirubin levels. The serum AST levels were compared in preoperative and postoperative period and there was significant increase in level of serum AST.
The serum ALT levels comparison between preoperative and postoperative values has shown significant change. The difference in serum alkaline phosphatase levels is also non significant. No major complications were encountered during laparoscopic cholecystectomy. 


\section{Discussion}

Liver function tests are used as an indicator of duct obstruction in preoperative period and duct injury or ligation in postoperative period. The serum alkaline phosphatise is raised in bile duct obstruction. The liver functions are immediately deranged in bile duct and vascular injuries. Many studies have shown changes in liver function tests in patients undergoing laparoscopic cholecystectomy. ${ }^{6}$ Carboxy peritoneum may be the prime reason for the change in liver enzymes as carbon dioxide is not used in open cholecystectomy.

The bilirubin is transported, conjugated, stored and excreted by hepatic cells. The serum bilirubin levels are not significantly different in preoperative and postoperative estimation. Sakorafas et al studied the effect of pneumoperitoneum on serum bilirubin levels in preoperative and postoperative period of laparoscopic cholecystectomy. ${ }^{6}$ They concluded that no alteration in serum bilirubin levels occurs in postoperative period after laparoscopic cholecystectomy. ${ }^{7}$ Hasukic et al confirmed that serum bilirubin levels remained unchanged from baseline levels after laparoscopic cholecystectomy. ${ }^{8}$ The elevation of liver enzymes AST and ALT after uncomplicated laparoscopic cholecystectomy is considered as a fact. In our study there was statistically significant increase in ALT and AST levels in post operative period.

In a study by Hasukic et al the AST and ALT levels were increased more in standard pressure laparoscopic cholecystectomy as compared to low pressure laparoscopic cholecystectomy performed at a pressure of $7 \mathrm{~mm}$ of $\mathrm{Hg}^{8}$

An increase in liver enzymes up to $70 \%$ has been reported with good postoperative outcome in patients with laparoscopic cholecystectomy. ${ }^{9}$ The clinical importance of elevations of AST and ALT has not been specified but transient hepatic malfunction was considered in a previous study. It was suggested that increased intraperitoneal pressure, squeezing the liver by cranial retraction of gall bladder during laparoscopic cholecystectomy, use of cautery in liver fossa for haemostasis, manipulation of external biliary system and effects of general anaesthesia are the possible causes of elevation of liver enzymes. The rise in value of AST and ALT was statistically significant. Similar rise in liver enzymes was noticed in a study by Hasukic et al. ${ }^{8}$ This rise is due to the effect of creation of pneumoperitoneum which reduces the portal vein blood flow and cause alteration in liver function. An intra abdominal pressure of $15 \mathrm{~mm}$ of $\mathrm{Hg}$ can reduce hepatic perfusion by $39 \%$ resulting in rise of liver enzymes. ${ }^{10}$ Guven et al have found a transient elevation in ALT and AST after laparoscopic cholecystectomy. The results are consistent with other studies also who found significant rise in liver enzymes after laparoscopic cholecystectomy as compared to gasless cholecystectomy, underlining the absolute effect of intraperitoneal pressure on hepatic perfusion by means of changes in liver enzymes. ${ }^{11}$

Alkaline phosphatise ALP is an enzyme in the cell lining the biliary ducts of the liver. ALP levels in plasma rise with large bile duct obstruction, intrahepatic cholestasis, or infiltrative diseases of the liver. The rise in levels of ALP was not significant in this study. In a study by Fakar Hameed et al all the liver enzymes, liver enzymes with exception of ALP increased significantly 48 hours after surgery. However changes in ALP was insignificant. $^{12}$

Various mechanisms have postulated for increase in liver enzymes, the most common accepted is effect of carboxy peritoneum. This high pressure is responsible for reduced portal flow causing sublethal ischemia of hepatic cells leading to release of enzymes into circulation. ${ }^{12}$ The second mechanism is reperfusion injury due to sudden elevation and depression of intra abdominal pressure during laparoscopic surgery. This sudden alteration in intra abdominal pressure could cause the undulation of portal blood flow giving rise to ischemia re irrigation of hepatic sinusoids resulting in their damage. ${ }^{13}$ In third mechanism the increased intra abdominal pressure is thought to 
trigger neuro humoral response of the renninangiotensin-ldosterone system. ${ }^{14}$ Vasopressin and norepinephrin play a significant role of causing damage to liver cells thereby leading to increase in liver enzymes after laproscopic surgery.

\section{Conclusion}

This study concludes that transient elevation of liver enzymes does occur after laparoscopic cholecystectomy. The cause of this transient elevation has been attributed to carboxy peritoneum, reperfusion injury and neuro hormonal response to increased intra abdominal pressure. The transient elevation of liver enzyme in post operative period of laparoscopic cholecystectomy does not affect the post operative recovery.

\section{References}

1. Hashikura Y, Kawasaki S, Munakat Y. Effect of peritoneal insuffulation on hepatic and renal blood flow. Surg Endosc 1994;8:759-61.

2. Tan M, Xu FF, Peng JS, Li DM, Chen LH, Lv BJ et al. Changes in the level of serum liver enzymes after laparoscopic surgery. World J Gstroenterol 2003;9(2):364-7.

3. Barrat C, Capello E, Champault G. Intraperitoneal thermal variations during laparoscopic surgery. Surg Endosc 1999;13:136-8.

4. Giraudo G, Brachet CR, Caccetta M. Gasless laparoscopy could avoid alterations in hepatic function. Surg Endosc 2001;15:74-6.

5. Ischinose $\mathrm{K}$, Yanagi $\mathrm{F}$, Higashi $\mathrm{K}$. Recurrent transient increase in liver enzymes specifically after isoflurane anaesthesia. MASUI 1999;48:421-3.

6. Sakorafas G, Anagnostopoulos G, Stafyla V, Koletis T, Kotsifopoulos N, Tsikos S et al. Elevation of serum liver enzymes after laparoscopic cholecystectomy. N Z Med J 2005;118(1210):1317.
7. Schilling MK, Redaelli V, Krahenbuhi L. Splanchnic microcirculatory changes CO2 laparoscopy. J Am Coll Surg 1997;184: 378-82.

8. Hasukic S, Postoperative changes in liver function tests: Randomized comprision of low and high pressure laparoscopic cholecystectomy. Surg Endosc 2005;19 (11):1451-5.

9. Kotake Y, Takeda J, Matsumoto M. Subclinical hepatic dysfunction in laparoscopic cholecystectomy and laparoscopic colectomy. $\mathrm{Br} \mathrm{J}$ Anaesth 2001;87:774-7.

10. Elefteriadis E, Kotzampassi K, Botsios D, Splanchnic ischemia during laparoscopic cholecystectomy. Surg Endosc 1996;10:324-6.

11. Sato K, Kawamura T, Wakasawa R. Hepatic blood flow and functions in elderly patients undergoing laparoscopic cholecystectomy. Anesth Analg 2000;90:1198-1202.

12. Hameed F, Ahmed B, Khan A. Impact of pneumoperitoneum on hepatic functions after laparoscopic cholecystectomy. APMC 2009;3:100-6.

13. Nishiyama T, Yokoyama T, Hanaoka K. Liver function after sevoflurane or isoflurane anaesthesia in neurosurgical patients. Can J Anesth 998;45:753-75.

14. Tauro LF, Sheetal CM, Aithala PSM. Evaluation of effects of laparoscopic surgery on hepatic functions. Journal of Clinical Diagnosis and Research 2008;2(6):155-62. 